\title{
Accessory extensor digiti secundus muscle: some interesting facts
}

\author{
Elvy Suhana $\cdot$ Srijit Das
}

Received: 13 July 2011/Accepted: 7 September 2011/Published online: 23 September 2011

(C) Japanese Association of Anatomists 2011

We read with much interest the recently published article "A variation of the extensor hallucis longus muscle [accessory extensor digiti secundus (AEDS) muscle]" (Tezer and Cicekcibasi 2011). We wish to share our views on this scientific article. This variation is rare of its kind and the authors deserved praise for reporting such a rare variation.

The presence of this AEDS muscle is a mystery in terms of its evolution and incidence. No anatomy textbook mentions this anomaly. Accessory muscle slip has been reported earlier in a Japanese population. The present anomaly was observed on both sides of the same cadaver, suggesting a possible developmental defect in the musculoskeletal system. Interestingly, there are past reports on the existence of the accessory digiti arising from the extensor carpi ulnaris muscle in hand. An earlier study reported the presence of accessory digiti minimi in $34.2 \%$ of the hands of Kyushu Japanese (Nakashima 1993). These findings were similar to those of an earlier European study (Mestdagh et al. 1985).

The action of this muscle was not clearly mentioned in the article. The extensor hallucis longus originated from two-thirds along the inner surface of the fibula and attached to the distal phalanx of the big toe. Its actions are for extension of the big toe, dorsiflexion and inversion (Moore and Dalley 2006). The relation of the accessory slip to the dorsalis pedis artery and medial terminal branch of deep peroneal nerve was not mentioned. In a case of AEDS, it is possible that the medial terminal branch of the deep peroneal nerve supplying the web space between the 1 st and 2nd toe and the dorsalis pedis artery may be compressed. Indeed, the pulsations in the dorsalis pedis artery could be altered.

Overall, an interesting article with important clinical implications. The editor and the authors should be applauded for the publication of such an interesting article.

Conflict of interest None.

\section{References}

Mestdagh H, Bailleul JP, Vilee B, Bocquet F, Depreux R (1985) Organization of the extensor complex of the digits. Anat Clin 7:49-53

Moore KL, Dalley AF (2006) Clinically oriented anatomy, 5th edn. Lippincott Williams and Wilkins, Philadelphia, pp 638-642

Nakashima T (1993) An accessory extensor digiti minimi arising from extensor carpi ulnaris. J Anat 182:109-112

Tezer M, Cicekcibasi AE (2011) A variation of the extensor hallucis longus muscle (accessory extensor digiti secundus muscle). Anat Sci Int. doi:10.1007/s12565-011-0108-8
E. Suhana $(\bowtie) \cdot S$. Das

Department of Anatomy, Universiti Kebangsaan Malaysia, Jalan Raja Muda Abdul Aziz, 50300 Kuala Lumpur, Malaysia e-mail: elvysuhana@yahoo.com.my 